\title{
Starting Strong: An Exercise in International Learning
}

\author{
Peter Moss \\ University of London \\ United Kingdom
}

\begin{abstract}
Starting Strong, a comparative review of early childhood education and care (ECEC) in 20 countries organised by $\mathrm{OECD}$, is an important study. It provides a wealth of documentation, findings and conclusions. The article provides some background to the review, highlighting its broad, holistic, rights-based approach. It overviews some of the reviews main findings, including the widespread policy trends it identifies, as well as eight major policy conclusions and ten areas of policy option that 'major ECEC stakeholders' are recommended to consider. The article then offers the author's own perspective on why the review is so important; in particular, while offering valuable pointers to what works, i.e. technical issues, it also places in the public arena some of the most important political and ethical issues with which the development of ECEC confronts stakeholders. Five of these issues are discussed: the relationship between ECEC and school; national responsibility, decentralisation and democracy; the status, conditions and structure of the workforce; the question of paradigm; and pedagogical approaches. The article concludes by considering what might happen next. How do we take the work forward? How do we use this rich cross-national material? Suggestions made include: using the documentation from the review to deepen critical reflection on policy, provision and practice; developing exchange and dialogue between people and organisations in different countries, through which to learn with others about issues of common interest and concern; and using the method developed for doing Starting Strong to undertake reviews of ECEC on a regular basis.
\end{abstract}

Key Words : early childhood education, cross-national, OECD

\section{Introducing Starting Strong}

At a meeting in Reggio Emilia in Northern Italy in September 2006, attended by delegates from many countries, a report was launched and one of the most important international projects in early childhood came to an end. The report was called Starting Strong II, and it was the final chapter in a cross-national thematic review of early childhood education and care (ECEC) policy

Peter Moss, Professor of Early Childhood Provision, Thomas Coram Research Unit, Institute of Education, University of London. 27 Woburn square, London WC1H 0AA, UK Peter.Moss@ioe.ac.uk conducted over the previous eight years by the Organisation for Economic Cooperation and development $(\mathrm{OECD})^{1}$.

The review was launched in 1998 by OECD's Education Committee, and concluded in 2006, with the publication of Starting Strong II. It covered 20 of OECD's member states, the countries included having volunteered to participate and to contribute to the ensuing costs. Most of the countries taking part, 15, are European, mainly from Western European; only the Czech Republic and Hungary are in Central or Eastern Europe. The remaining five countries include the three members of the North American Free Trade Association (Canada, Mexico and the United States), Australia and 
just one Asian country, Korea (the only other Asian member of OECD is Japan). (For details of how the reviews were conducted, see endnote ${ }^{2}$ ).

The thematic review (referred to below as the Starting Strong review) includes a good spread of countries, or at least of rich countries. No international review, though, is likely to be able to cover every country, and there are, necessarily, some important omissions in Starting Strong. For example, I am quite convinced that the future of early childhood education and care lies in a fully integrated service for children from birth to 6 years, rather than the split services that are still widespread. Some countries that have integrated their services have done so into the welfare system. But most integrated services today are in education systems. Unfortunately some of these countries, such as Brazil and Slovenia, were not OECD member states at the time of the Starting Strong review; others that were members, such as Iceland, New Zealand and Spain, chose not to participate in the review; while others, such as England, Norway and Sweden were reviewed in the first round of the review, some time ago, and soon after or before the transfer into education. The Starting Strong review, therefore, does not offer a comprehensive and current cross-national review and evaluation of this important reform movement. This, in my opinion, should be a priority for future work - for Starting Strong III!

The main findings and conclusions from the thematic review are contained in two major OECD reports: Starting Strong I, published in 2001 and launched in that year at a conference in Stockholm, and Starting Strong II, published in 2006; both are available on the OECD website but must be purchased. These reports were written by John Bennett, who led the entire review for OECD, along with two colleagues, Michelle Neuman, who played a leading role in the first 12 reviews and in writing Starting Strong I, and Colette Taylor, who worked on Starting Strong II.

The documentation produced by the review, both national and comparative, is an invaluable resource for anyone interested in ECEC; while the review itself is the most important cross-national study we have had in this field, both for the breadth of material it has brought together and for the rigour and depth of its analysis and conclusions. Moreover, the review addresses policy and provision and practice, an unusual combination in crossnational studies. It is also striking for what has been described as its 'egalitarian, rights-based approach', which places the interests - and rights - of the child at the centre. OECD is an organisation primarily concerned with economic issues, such as employment and productivity; it is therefore a (pleasant) surprise to find the Starting Strong review so concerned not only with children as active subjects, but "taking a broad and holistic approach that considers how policies, services, families, and communities can support young children's early development and learning" (OECD, 2006, p.12).

The economic dimension is present, but so too are social, cultural, educational, gender and demographic dimensions: the review's claim to take "a broad and holistic approach" (OECD, 2006, p.12) is not an empty boast. The review, therefore, avoids the excessively economic and instrumental focus of too many policy reports in this field, recognising the cultural, social and political value and meaning of ECEC services and their many possibilities. And it keeps before us the image of the child, not as an object to be readied for some future national mission of survival, but as a subject living her everyday life in early childhood education and care services and able and willing to be an active participant in this space. Indeed, in the concluding chapter of the second Starting Strong report, policy makers are urged to "place well-being, early development and learning at the core of ECEC work, while respecting the child's agency and natural learning strategies". 3

In the rest of this paper, I will overview the main conclusions of the review, as set out in the Starting Strong reports, then introduce a more personal perspective, explaining why I find the review so important. I will end by asking how we can take forward and utilise the review's good work. 


\section{An Overview of the Starting Strong Reports}

Starting Strong I identifies what it terms "seven cross-national policy trends", which can be observed, to a greater or lesser extent, in most countries:

1. expanding provision;

2. raising the quality of provision

3. promoting coordination and coherence of policy and services;

4. exploring strategies to ensure adequate investment

5. improving staff training and work conditions

6. developing appropriate pedagogical frameworks for young children

7. engaging parents, families and communities.

Under the heading of "policy lessons from the thematic review', this initial report also identifies eight "key elements of policy that are likely to promote equitable access to quality ECEC" (OECD, 2001, p.11):

1. A systematic and integrated approach to ECEC policy, including a clear vision, a coordinated policy framework and a lead department in government.

2. A strong and equal partnership with the education system, supporting a lifelong learning approach, smooth transitions and recognising ECEC as an important part of the education system.

3. A universal approach to access, with particular attention to children in need of special support, highlighting the need for more attention to be paid to access for children under three years.

4. Substantial public investment in services and infrastructure, essential to support a sustainable system of quality, accessible services.

5. A participatory approach to quality improvement and assurance, that engages children, parents and staff.

6. Appropriate training and working conditions for ECEC staff, and strategies to recruit and retain a qualified and diverse, gender-mixed workforce.

7. Systematic attention to data collection and monitoring, covering the status of young children, ECEC provision and the early childhood workforce.

8. A stable framework and long-term agenda for research and evaluation, with sustained investment to support research on key policy areas.

The second Starting Strong report is organised around these eight key policy elements, and draws on updated information for the first 12 countries to be reviewed as well as new information from the eight countries covered in the second stage of the review. There is also an extensive annex, giving overviews of ECEC policy and services in all 20 countries. Of particular interest is the final chapter, which sets out "ten policy option areas for consideration by governments and major ECEC stakeholders" (OECD, 2006, p.16) - what might be considered Starting Strong's final messages.

1. To attend to the social context of early childhood development, so that services are organised in a manner "that serves important social and economic objectives, such as, ensuring labour supply, equality of opportunity for women, family well-being and social inclusion" (OECD, 2006, p.16).

2. To place well-being, early development and learning at the core of ECEC work, while respecting the child's agency and natural learning strategies: services for children under 3 years "have often been seen as an adjunct to labour market policies... with weak developmental agendas"; while services for children aged 3 to 6 years often place children in "pre-primary classes, with staff who are too few in number and inadequately qualified (OECD, 2006, p.16).

3. To create the governance structures necessary for system accountability and quality assurance, for example strong policy units, a data and monitoring office, an evaluation agency and a training authority.

4. To develop with the stakeholders broad guidelines and curricular standards for all ECEC services, 
"proposing broad pedagogical orientations rather than detailing what should be taught". Of particular importance to the well-being and learning of children are "a focus on the agency of the child... and the extensive use of listening, project work and documentation" (OECD, 2006, p.16).

5. To base funding estimates on achieving quality pedagogical goals. "According to reliable cost estimates, most countries need to double annual investment per child to ensure acceptable childstaff ratios and high qualified staff" (OECD, 2006, p.17).

6. To reduce child poverty and exclusion through upstream fiscal, social and labour policies, and to increase resources within universal programmes for children with diverse learning rights. Children with disabilities or from disadvantaged backgrounds should be included in universal programmes: "targeted programmes segregate, may stigmatise and generally fail to provide for many of the children eligible" (OECD, 2006, p.17).

7. To encourage family and community involvement in early childhood services: "families play a central nurturing and educational role in their children's lives...[and] should be assisted by early childhood centres and staff to support their children's development and learning" (OECD, 2006, p.17).

8. To improve the working conditions and professional education of ECEC staff, "attention to the level of recruitment of early childhood workers, their professional education and work conditions [being] key to quality services" (OECD, 2006, p.17).

9. To provide autonomy, funding and support to early childhood services: "once goals and programme standards for early childhood services have been decided in the national framework documents, educators and services should have the autonomy to plan, and to choose or create curricula that they find appropriate" (OECD, 2006, p.17).

10. To aspire to ECEC systems that support broad learning, participation and democracy, so that "the early childhood centre becomes a space where the intrinsic value of each person is recognised, where democratic participation is promoted, as well as respect for our shared environment" (OECD, 2006, p.18).

\section{Why Starting Strong Is So Important: A Personal Perspective}

The Starting Strong review offers a wealth of information and analysis, which provide a strong basis for making decisions about what might be termed technical matters: what structures and procedures are best suited to achieving goals and purposes. For example, the Starting Strong reports offer important findings and conclusions on investment levels and funding mechanisms. Comparing current levels of public investment against the needs of a quality programme, Starting Strong II concludes that "the case can be made that $1 \%$ of GDP is a minimum figure [for public investment] if adequate quality is to be maintained" (OECD, 2006, p.105). Currently, though, many countries (including the UK, the US, Germany, Italy and Australia) spend 0.5 per cent or less, while most Nordic countries spend over 1.5 per cent. Overall, the report concludes, "OECD countries with the exception of the Nordic countries - are underspending...the evidence suggests that direct public funding of services brings [more advantages] compared with parent subsidy models".

But while technical questions and answers matter, they need, I believe, to be put in their rightful place. A theme in my own work in recent years has been the urgency of reclaiming early childhood education and care as, first and foremost, a political and ethical subject - rather than simply an exercise in technical practice (Dahlberg \& Moss, 2005; Moss, 2007). From this perspective, Starting Strong II is an important document. 
While offering valuable pointers to what works, it also places in the public arena some of the most important political and ethical issues with which the development of ECEC confronts stakeholders. Let me give five examples.

\section{ECEC and School}

At a time when "an instrumental and narrow discourse about readiness for school is increasingly heard" (OECD, 2006, p.219), producing strong pressures to treat ECEC as simply a training ground for compulsory schooling, the Starting Strong review problematises this discourse and provokes us to ask more fundamental questions. What are the dangers of a relationship based on a "downward pressure on ECEC to adopt the content and methods of the primary school", a process some have termed 'schoolification'? How, in the words of the first report, can we create a 'strong and equal partnership' between ECEC and school, based on a new pedagogical meeting place? What would that partnership and meeting place look like? Should we today be talking about preparing children for school? Or should we be talking about, as the conclusions of Starting Strong II say, how to "prepare schools for young children"?

With this question, Starting Strong II turns the spotlight on the school itself. And it turns up the intensity of that spotlight when it argues that the:

"Organisation, curriculum and decision-making in schools continue to resemble $19^{\text {th }}$ century patterns: curricula imbibed with the certainties of the past, formal testing of discrete skills and knowledge items, and the 'balkanisation' of teachers into separate classrooms and disciplines. The school as an educational institution cannot continue in [its current] way" (OECD, 2006, p. 221-222).

The report goes on to pose an alternative way for the school to go, which suggests ECEC services influencing the school:

"Knowledge is inter-disciplinary and increasingly produced in small networks. In the future, it will be constructed through personal investigation, exchange and discussion with many sources, and co-constructed in communities of learners characterised by team teaching. This approach to knowledge can begin in early childhood and, in fact, fits well with the child's natural learning strategies, which are fundamentally enquiry based and social " (OECD, 2006, p.222).

Starting Strong has turned a widely heard argument on its head. In doing so it suggests two further and profound political and ethical questions - what is a good education? what do we want for our children? questions that have been marginalised by the current technical discussion about 'school readiness' which fuels the worrying tendency, noted in Starting Strong II, "of seeing the school as the benchmark".

\section{National Responsibility, Decentralisation and Democracy}

At a time when educational discourse increasingly combines a rhetoric of (individual) choice with a practice of standardisation, the Starting Strong review asks us to think more critically about the relationship between uniformity and diversity, centralisation and decentralisation, individual and collective choice. The report's conclusions propose a national framework of entitlements, values and goals, including broad curricular guidelines; and strong decentralisation, allowing space for local autonomy, interpretation and innovation - and, therefore, the practice of democracy.

"The decentralisation of management functions to local authorities is a gauge of participatory democracy. At the same time, the experience of ECEC policy reviews suggests that central governments have a pivotal role in creating strong and equitable early childhood systems, and in co-constructing and ensuring programme standards... In this vision of administration, the state can become the guarantor of democratic discussion and experimentation at local level, instead of simply applying policies from the centre" (OECD, 2006, p.220).

At the same time, the report recognises that certain conditions are needed if this relationship is to work, including adequate funding, strong infrastructure, well 
educated staff and pedagogical documentation, a tool which has a central role to play in a decentralised and democratic approach to early childhood education and care. The lesson I draw is that while "decentralisation is necessary for effective governance", it is risky, difficult and needs constant thought, strong structures and tools, and regular evaluation.

Effective decentralisation and democracy are closely connected; decentralisation is a condition of democracy, but democracy is also a condition for effective decentralisation - or local autonomy. Democracy, too, Starting Strong II implies should be at the heart of ECEC services, a fundamental value and practice. I have already noted the conclusion that ECEC systems should support "participation and democracy". This means an upbringing for children that foregrounds democratic ways of living: "In addition to learning and the acquisition of knowledge, an abiding purpose of public education is to enhance understanding of society and encourage democratic reflexes in children" (OECD, 2006, p.219). This important role for education is currently at risk.

"Today, society seems to be less concerned with such [democratic] ideals. Reflecting the growing marketisation of public services, consumer attitudes toward education and knowledge are increasing. Individual choice is put forward as a supreme value, without reference to social cohesion or the needs of the local community. In many schools, a focus on 'test-prep' knowledge threatens the broad liberal arts tradition that sustained in the past informed and critical thinking" (OECD, 2006, p.219).

Here, indeed, is further strong criticism of much of today's education and schools, with the final report raising serious concerns about the increasing trend to marketisation and privatisation of services and the consequences for democratic values and practice.

But democracy is not just about children. Parental involvement also has a strong democratic dimension, being "the exercise by parents of their basic right to be involved in the education of their children" (OECD, 2006, p.219). So, too, does policy making: “a major underlying lesson from the OECD reviews is that sound policy cannot be a quick fix from outside but more a matter of democratic consensus generated by careful consultation with the major stakeholders" (OECD, 2006, p.206).

This strong commitment to democracy as a key value also underpins the image of ECEC services in the second Starting Strong report. It proposes "a vision of early childhood services as a life space where educators and families work together to promote the well-being, participation and learning of young children", and argues that this vision must be "based on the principle of democratic participation" (OECD, 2006, p.220). This image (and others in the report, such as early childhood centres as "communities of learners") has much in common with the image proposed by Gunilla Dahlberg, Alan Pence and myself in our book 'Beyond Quality in Early Childhood Education and Care', of "[early childhood institutions] as public forums in civil society in which children and adults participate together in projects of social, cultural, political and economic significance" (Dahlberg, Moss, \& Pence, 2007, p.73). This image has in turn been inspired by the thought and practice of Reggio Emilia:

The early childhood services of Reggio Emilia insist on the importance of viewing public services as a collective responsibility and offer us an understanding of the school as first and foremost a public space and as a site for ethical and political practice - a place of encounter, interaction and connections among citizens in a community, a place where relationships combine a profound respect for otherness and difference with a deep sense of responsibility for the other, a place of profound interdependency. In their work, the teachers of Reggio have struggled to realise the emancipatory potential of democracy, by giving each child possibilities to function as an active citizen and to have the possibility of a good life in a democratic community (Dahlberg \& Moss, 2005b, p.10).

There are, of course, other images of early childhood institutions. Two are very prominent, at least in the Anglo-Saxon world of neoliberal economies: the 
early childhood institution as an enclosure where technology can be applied to produce predetermined outcomes (the metaphor is the factory); and the early childhood institution as a business, selling a commodity to consumers. The Starting Strong review has avoided uncritical adoption of these images, offering instead a very different and more subtle understanding of what early childhood services might be.

It is worth noting here that Starting Strong exceptionally in policy documents in my experience does recognise the importance of social constructions or images, whether of the child or the early childhood institution. It does not assume there is only one true way of seeing or understanding: there is acknowledgement that we have choices - and our choice of image is deeply ethical and political. Starting Strong I, for example, quotes Carlina Rinaldi speaking about the experience of Reggio Emilia: "One point appears to us to be fundamental and basic: the image of the child" and goes on to propose that policy makers "become aware of national or cultural constructions, and their impact on the indicators of quality put forward by different stakeholders" (OECD, 2001, p.63).

\section{The Workforce}

Starting Strong II concludes that many countries have a long way to go before achieving a well educated and paid workforce: "[The situation of staff and levels of training in ECEC across the countries covered] is mixed, with acceptable professional education standards being recorded in the Nordic countries but only in early education in most other countries... [There] is a wide pay gap between child care staff and teachers, with child care staff in most countries being poorly trained and paid around minimum wage levels" (OECD, 2006, p.15). The review is also clear on the need for improvement: a well educated workforce is required, it argues on the basis of research evidence, for quality services and children's learning.

I would add two other arguments to support this position. First, equality. Why should young children require or get less than school children? Why should the workforce be devalued and treated so inequitably? Second, because new understandings of the complexity and importance of the work, including an understanding of early childhood services as sites of ethical and democratic practice, require a workforce with parity - in terms of qualification and pay - to school teachers (see Moss, 2006 for a discussion of the early childhood worker as a reflective and democratic professional).

But the political and ethical issues go deeper. Industrial societies have based their services for young children (but also those for elderly people) on exploiting an abundant supply of women with low levels of education, who have been prepared to work in services for poor pay and conditions. The underlying assumption has been that work with children and elderly people is something women are naturally suited for and is of intrinsically low value. This is neither desirable - nor sustainable: the traditional supply is diminishing as women become better qualified and have access to a widening range of occupations (Cameron \& Moss, 2007). The ethical questions involve the acceptability of exploiting cheap labour to undertake important and demanding work; the political questions concern whether societies are willing to rethink, revalue and degender the work.

A few countries - such as Denmark, Sweden and New Zealand - have made the commitment to rethinking and revaluing work with young children, moving towards a mainly graduate workforce. This partly explains their higher levels of public expenditure on ECEC. But only Norway, as far as I know, has a serious commitment to degender with a national target for male workers. Elsewhere, politicians either do not see the issue or else hope it will go away with some minimal concessions.

\section{The Question of Paradigm}

Starting Strong II makes visible the existence of different paradigmatic views of the world. It recognises how 'socio-cultural analysis and post-modernist 
research' are helping to expand ECEC research agendas: "a wider research perspective using other focuses, disciplines and approaches can be seen emerging in the ECEC field" (OECD, 2006, p.193). While in its concluding chapter, the report again refers to "postmodernists [arguing] that the old certainties of history, culture, structures and knowledge are weakening". It also references a few publications whose authors are working within a postmodern or poststructural paradigm.

Such recognition of diversity is rare in mainstream policy documents, which typically confine themselves to work produced within a positivistic paradigm - as if there was no other way of thinking about, researching and practicing ECEC. In my view, one of the major issues in the field of ECEC today is a widening divide between the mainstream, operating in a positivistic or modernistic paradigm; and a growing minority who are contesting this paradigm and developing new practices within alternative paradigms, one of which might be called postmodern, poststructural or postpositivistic. For the former, early childhood education is progressing inexorably to its apotheosis, based on the increasing ability of modern science to provide indisputable and universally applicable evidence of what works. While for the latter, early childhood education offers the prospect of infinite diverse possibilities informed by multiple perspectives, local knowledges, provisional truths: no final answer with closure, but the prospect of opening up to new understandings and new practices.

I have no time to go into this issue further and refer you to the growing literature on postmodern and poststructural theory and practice in early childhood education and care. But in my view the growing paradigmatic divide and the failure of most policy documents to recognise the issue are profoundly worrying. The absence of dialogue and debate impoverishes early childhood and weakens democratic politics. 'Mainstream' policy and practice are isolated from an important source of new and different thought, policy makers having little or no awareness of a growing movement that questions much of what they take (or have been advised to take) for granted. The dominant positivistic discourse is given too much uncritical space. In this situation, policy and practice choices are reduced to narrow and impoverished technical questions of the 'what works?' variety. (For a fuller discussion of the 'paradigmatic divide' in ECEC and whether some attempt can and should be made to bridge this divide, see Moss, 2007).

\section{What Pedagogy?}

The Starting Strong review and both its reports pose their own critical questions and provoke in us others. Not only do they reclaim early childhood education and care as a democratic project, they also remind us that it should be the subject of democratic debate - because we are confronted by choices, and choices that are political and ethical in nature. I have already mentioned some: the image of the child and the early childhood service; relationships between central and local, standardisation and diversity, ECEC and school; diversity of paradigm. Another choice, highlighted in Starting Strong, is in pedagogical orientation.

Starting Strong II identifies two common orientations: what it calls the 'pre-primary' and the 'social pedagogy' approaches. The former approach is most commonly found in English-speaking countries, though France is another example: "in addition to a downward transfer of subject fields, programme standards and pedagogical approaches from the primary school towards kindergarten, common teacher education is also practiced in several pre-primary systems (OECD, 2006, p.61). In the latter approach, ECEC services retain a strong identity distinct from the school; social pedagogy treats care, upbringing and education as an inseparable whole and places importance on work with the whole child, broad developmental goals, interactivity with peers and educators and quality of life; and it seeks a balance between culturally-valued topics of learning (such as, music, song, dance, environmental themes) and supporting the child's meaning-making acquired through relationships and experience of the world. "In countries inheriting a social pedagogy tradition (Nordic and 
Central European countries), the kindergarten years are seen as a broad preparation for life and the foundation stage of lifelong learning" (OECD, 2006, p.13).

Starting Strong II cites a number of examples of how these approaches differ in policy and practice. In early childhood curricula, for example, "the early education tradition generally results in a more centralising and academic approach to curriculum content and methodology, while pedagogical frameworks in the social pedagogy tradition remain more local, child-centred and holistic". Or, to take another example, the relationship between ECEC and school, "[in the social pedagogy approach] rather than 'schoolifying' ECEC services, there is a strong belief that early childhood pedagogy should permeate the lower classes of primary school... [Countries adopting the pre-primary approach] tend to introduce the contents and methods of primary schooling into early education" (OECD, 2006, p.59, 61). (for a fuller discussion of the relationship between ECEC and compulsory schooling, see Woodhead \& Moss, 2007).

There may well be other approaches to be identified, not to mention many different pedagogical theories, which can be cross-cutting influences on these broad approaches. The point, however, is that each approach and theory is inscribed with particular understandings, values and goals, from which emerge different ideas about practice and organisation. There is no objective way in which we can say which is best, all we can strive for is to understand better ways of working within each approach. Before research, we must make choices, political and collective - and we must take responsibility for the choices we make.

\section{What Next?}

The early childhood field owes a debt of gratitude to what has been a landmark in the cross-national study of early childhood education and care. OECD is to be congratulated for undertaking this work, but above all I want to acknowledge the invaluable contribution of John Bennett, who has led the review from beginning to end.
The review has both started and finished strong - and that is in large measure due to John, ably supported by Michelle Neuman, Colette Taylor and the national coordinators who supported the review teams visiting each country.

OECD and John Bennett have done their work, and done it well. This places a responsibility on the rest of us - whether governments, organisations or individuals. How do we take the work forward? How do we use this wonderfully rich source of cross-national material?

There may be some learning from other countries, seeing an interesting approach elsewhere that might in some form be worth importing. But the report rightly warns us against "fast-track policy transfer". Rather, in the report's own words, the review “opens up a range of policy options and allows participants to discuss and question taken for granted assumptions". Here, in my mind, lies its greatest value: reminding us that we do have choices and provoking critical thinking, so putting a stutter in dominant policy and research discourses. It should also stimulate a desire to learn with, not just from, other countries and to make this co-constructive learning a permanent process.

So what to do to make good use of the work already done and to take it forward? OECD has initiated a network of countries, who had their first meeting in 2007 and will continue to meet on a regular basis to dialogue and exchange on particular issues. The network is hosted by the Flemish government of Belgium and John Bennett acts as consultant to the network. Most countries that took part in the review are now members of the network, plus some others.

What else? I would like to suggest three possible actions that could be taken nationally or locally: I am sure there are more and the important point is that many people should be asking the question, what next? First, the existing documentation, especially the two Starting Strong reports, can and should be used to deepen critical reflection on policy, provision and practice. Properly used, the documentation should be a constant provocation, helping to make the familiar strange and so challenging taken-for-granted assumptions. Why do we do that? 
Why have we never done that? What are the effects of doing ECEC in one way or another? Starting Strong can be used at all levels for this purpose: on a college course or in a local early childhood service, within a local community, or by a regional or national government or organisation.

Second, the reports can be used as a resource to help develop exchange and dialogue between people and organisations in different countries, through which to learn with others about issues of common interest and concern. This can be on a one-off basis (a seminar or conference) or on a more regular basis (for example, an annual Round Table that brings together representatives from different countries). An example that interests me in particular is developing exchange and dialogue between countries that have integrated responsibility for all ECEC services in education (for example, Brazil, England, New Zealand, Norway, Slovenia, Spain and Sweden), but there are many other potential subjects.

Third, countries could use the method developed for doing Starting Strong to undertake reviews of ECEC on a regular basis. While it would be ideal for OECD to undertake the exercise again, across a wide range of countries, there is no guarantee this will happen. In the meantime, individual countries could take the initiative, inviting teams, made up of external experts, to revisit and review their ECEC policies and services, say 10 years after the last Starting Strong review, to provide an updated evaluation of policy, provision and practice.

The beauty of Starting Strong is that it offers some broad principles that might be applied generally, but these are seen as enabling and supporting more local diversity and experimentation. It makes no attempt to offer a universal and detailed guide to policy and practice, a global 'best practice' template. Instead it provokes us to think, opening up rather than closing down possibilities.

\section{References}

Cameron, C., \& Moss, P. (2007). Care work in Europe:
Present understandings and future directions. London: Routledge.

Dahlberg, G., \& Moss, P. (2005a). Ethics and politics in early childhood education. London: Routledge.

Dahlberg, G., \& Moss, P. (2005b). Introduction to Rinaldi, C. In Dialogue with Reggio Emilia: Listening, researching and learning. London: Routledge.

Dahlberg, G., Moss, P., \& Pence, A. (2007). Beyond quality in early childhood education and care; Languages of evaluation (2nd Ed.). London: Routledge.

Mahon, R. (in press). Learning, forgetting, rediscovering: Producing the OECD's 'new' family policy. In K. Martens, \& A. Jakobi (Eds.), Mechanisms of OECD Governance: International incentives for national policy making. London: Palgrave.

Moss, P. (2007). Meetings across the paradigmatic divide. Educational Philosophy and Theory, 39(3), 229-245.

OECD (2001). Starting Strong: Early childhood education and care. Paris: OECD Publications.

OECD (2006). Starting Strong II: Early childhood education and care. Paris: OECD Publications.

Woodhead, M., \& Moss, P. (Eds.). (2007). Early education and primary education. Early childhood in focus 2. Milton Keynes: Open University. Available at http:/www.bernardvanleer.org/ publication_store/publication_store_publications/ea rly_childhood_and_primary_education_transitions _ in_the_lives_of_young_children/file

\section{Notes}

1 The Organisation for Economic Cooperation and Development was established in 1961 and is based in Paris. It "brings together the governments of countries committed to democracy and the market economy from around the world to: support sustainable economic growth; boost employment; raise living standards; maintain financial stability; assist other countries' economic development; and contribute to growth in world trade" (http://www.oecd.org/ 
pages/0,3417,en_36734052_36734103_1_1_1_1_1,00.html). It currently has 30 members, drawn from the richest countries in the world. Original membership was based on non-Communist countries from Western Europe and North America, which have since been joined by Japan, Finland, Australia, New Zealand, the Czech Republic, Hungary, Poland, the Slovak Republic, Korea and Mexico. Chile, Estonia, Israel, the Russian Federation and Slovenia have recently been invited to join.

${ }^{2}$ For each participating country, a review team was assembled by OECD, consisting of 5 or 6 members, led by a member of the OECD group coordinating the review and accompanied by experts from other OECD member states; the country to be reviewed offered a national coordinator to liaise with and support the review team. In the case of the Korean review, the team was led by John Bennett, OECD's programme manager for the whole Starting Strong review, and the remainder of the team consisted of experts from Australia, Canada, Hungary and the Netherlands. Before a team arrived in the country to be reviewed, it received a background report prepared by the national government (either directly or by an organisation contracted to undertake this task), providing a wide range of information about policy, provision and practice. The team spent up to two weeks in the country under review, visiting a range of services and talking with many organisations and individuals from a variety of backgrounds (e.g. government, NGOs, research, trade unions). Following the visit, the rapporteur for the team drafted a country note, in collaboration with OECD, providing an account of the visit and the team's observations and conclusions. The draft note was then discussed with the government of the reviewed country, before a final version was agreed and put in the public domain.

The end result of the review process is a wide range of documentation, including background reports and country notes for each of the countries in the review, all downloadable free of charge from OECD's website (http://www.oecd.org/document/3/0,2340,en_2649_201185 27000067_1_1_1_1,00.html), and the two Starting Strong reports.

${ }^{3}$ An interesting contrast can be made between the Starting Strong review and another OECD thematic review carried out at the same time, Babies and Bosses (2001-2005), which focused on 'family friendly' policies, including the provision of ECEC services. Babies and bosses covers 13 countries, 10 of which were also included in Starting Strong, and adopted a very different approach, focused far more on labour market participation and a liberal economic perspective. The two reviews, though from the same organisation, come up with very different perspectives and conclusions; for example, Babies and Bosses shows a clear preference for cheaper forms of provision and demand-side funding mechanisms (for a fuller discussion of these two OECD reviews, see Mahon, in press). 